\title{
BESONDERS PRAKTISCH FÜR DEN KOLONISTEN: UMA ANÁLISE DOS CLASSIFICADOS DO JORNAL IMMIGRANT DE 1883 A 1888
}

\section{BESONDERS PRAKTISCH FÜR DEN KOLONISTEN: EINE ANALYSE DER ANZEIGEN DER IMMIGRANT ZEITUNG ZWISCHEN 1883 UND 1888}

\author{
Daniela Cristina Graupner Brandão \\ Graduada em Letras Alemão pela Universidade Regional de Blumenau. \\ Professora de alemão do Colégio Sinodal Doutor Blumenau em Pomerode/SC \\ E-mail: dgraupnerbrandao@yahoo.com.br \\ Valéria Contrucci de Oliveira Mailer \\ Professora da Universidade Regional de Blumenau \\ Membro do Grupo de Pesquisa "Políticas de Educação na Contemporaneidade" \\ E-mail: vmailerbr@yahoo.de
}

\section{RESUMO}

A imprensa em língua alemã contribuiu sobremaneira para a estruturação e desenvolvimento das colônias no sul do Brasil. Além de oferecer informações sobre o país e o exterior, unificava o grupo de imigrantes por meio da língua, uma vez que muitos vinham de regiões diferentes da Alemanha com dialetos também diversos. O presente trabalho tem por objetivo analisar os anúncios do jornal Immigrant, que circulou na Região do Vale do Itajaí entre os anos de 1883 e 1891. Trata-se de uma pesquisa qualitativa com análise documental e a metodologia consistiu na tradução dos anúncios do alemão gótico, posterior categorização, sistematização em dados numéricos e por fim, geração de gráficos classificados por segmento: estilo, tamanho, língua, localização e etnia. As análises contribuíram para uma melhor compreensão desse período da imigração alemã, bem como possibilitaram a percepção de parte do contexto histórico-cultural e econômico da época, além do perfil dos anunciantes e dos destinatários, legitimando assim a função social da imprensa.

Palavras-chave: Anúncios. Immigrant. Imigração Alemã. Vale do Itajaí.

\section{ZUSAMMENFASSUNG}

Die deutschsprachige Presse hat einen erheblichen Beitrag zur Strukturierung und Entwicklung der Kolonien im Süden Brasiliens geleistet. Sie bot nicht nur Informationen über das In- und Ausland, sondern einte die Gruppe der Einwanderer durch die Sprache, da viele aus 
verschiedenen Gebieten Deutschlands stammten und unterschiedliche Dialekte sprachen. Ziel der vorliegenden Arbeit ist es, die Anzeigen der Zeitung Immigrant zu analysieren, die zwischen 1883 und 1891 in der Region des Itajaí-Tals erschien. Es handelt sich hierbei um eine qualitative Forschungsarbeit mit Dokumentenanalyse. Die Methodik bestand in der Übersetzung der Anzeigen in altdeutscher Schrift, einer späteren Kategorisierung, numerischen Systematisierung und der Erstellung von Diagrammen, die nach folgenden Bereichen gegliedert sind: Stil, Größe, Sprache, Ort und Ethnie. Die Analysen haben zu einem besseren Verständnis dieser Zeit der deutschen Einwanderung beigetragen und die Wahrnehmung eines Teils des geschichtlichkulturellen und wirtschaftlichen Kontextes dieser Zeit sowie des Profils der Inserenten und Adressaten ermöglicht. Dadurch wird die wichtige gesellschaftliche Rolle der Presse bestätigt.

Schlüsselwörter: Anzeigen. Immigrant. Deutsche Einwanderung. Itajaí-Tal.

\begin{abstract}
The German-language press greatly contributed to the structuring and development of the colonies in southern Brazil. In addition to providing information on the country and abroad, it unified the immigrant group through language, since many came from different regions of Germany with diverse dialects. The present work aims to analyze the advertisements of the Immigrant newspaper, which circulated in the Region of the Vale do Itajaí between the years 1883 and 1891. This is a qualitative research with documentary analysis and the methodology consisted in the translation of the ads from the Gothic German, subsequent categorization, systematization in numerical data and, finally, generation of charts classified by segment: style, size, language, location and ethnicity. The analysis contributed to a better understanding of this period of German immigration, as well as allowed the perception of part of the historical-cultural and economic context of the time, along with the profile of the advertisers and the recipients, thus legitimizing the social function of the press.
\end{abstract}

Key-words: Ads. Immigrant. German Immigration. Vale do Itajaí.

\title{
1 INTRODUÇÃO
}

Os baluartes da imigração alemã no Brasil foram escolas, igreja evangélica e imprensa. A imprensa alemã, principalmente no sul, teve papel fundamental na vida dos imigrantes, seus descendentes e das colônias que estavam por se formar. Além de dois grandes jornais de grande circulação, o Blumenauer Zeitung (Gazeta Blumenauense) e o Der Urwaldsbote (Commercio de 
Blumenau), aqui também circularam revistas, almanaques (Kalender), folhetos religiosos e jornais carnavalescos (apareciam esporadicamente) das mais diferentes orientações, que eram aguardados ansiosamente, pois traziam críticas políticas e sociais, sempre com sarcasmo e ironia. Entre eles: Die Mistgabel (A Forquilha de Esterco), Die Schnauze (O Boca Grande), Die Gurke (O Pepino), Der Mosquito (O Mosquito) (FERREIRA DA SILVA, 1977).

O Blumenauer Zeitung teve seu primeiro exemplar publicado em 1881, tendo como redator Hermann Baumgarten. Já o Der Urwalsbote surgiu com o desaparecimento do jornal Immigrant em 1891, sob a direção do Pastor Faulhaber, que adquiriu suas instalações e deu início em 1893 às primeiras edições. Teve a princípio orientação exclusivamente religiosa como porta-voz dos interesses das Comunidades Evangélicas do Município e das escolas. Em 1898 assume a redação do jornal Eugen Fouquet, bacharel em direito e jornalista e dá ênfase à campanha política municipal (MAILER, 2003).

O jornal Immigrant, portanto, o segundo jornal do município, teve como redator Bernardo Scheidemantel e circulou de abril de 1883 a abril 1891, de tendência progressista e defensor da república entrou em confronto com o Blumenauer Zeitung, de cunho conservador e monárquico, o que lhe custou a perda de aliados levando ao fim de suas atividades (SILVA, 1977). Publicado totalmente em língua alemã, saía toda quarta-feira e circulou por um período de tempo reduzido em comparação ao seu rival. Seu formato era retangular com dimensões de 21 $\mathrm{cm} \times 45 \mathrm{~cm}$ e era diagramado em três colunas por página. A capa seguia um padrão, na qual constavam em cabeçalho a data de publicação do jornal, a localização dos distribuidores, o seu valor de mercado e o número da edição. No corpo da página inicial podia-se perceber a presença de agentes distribuidores dos jornais e as chamadas para as principais publicações (O NASCIMENTO..., 2014).

Ainda segundo pesquisa do curso de jornalismo da FURB (O Nascimento..., 2014), o jornal constitui uma rica fonte em relatos sobre sua época, uma vez que possibilita a análise de informações sob diferentes pontos de vista. As edições ainda existentes do Immigrant são, entretanto, escassas e encontram-se no Arquivo Histórico José Ferreira da Silva em Blumenau.

Dessa forma, este estudo pretende contribuir para elucidação de parte do contexto local, tendo por objetivo a análise e compreensão das informações contidas nos anúncios do jornal Immigrant. É uma pesquisa documental qualitativa, cuja metodologia de trabalho pautou-se na tradução da língua alemã gótica para língua alemã latina e posteriormente para língua portuguesa, nos oito exemplares escolhidos aleatoriamente e que compreendem a amostragem do período de 1883 a 1888 . 
As análises dos anúncios do Immigrant abrangeram os seguintes aspectos: estética, tamanho, função social, etnia, perfil dos anunciantes e destinatários, análise linguística, produtos e serviços ofertados e recorrências, levando em conta o contexto histórico, social e cultural dos imigrantes alemães em solo brasileiro, mais especificamente, na região do Vale do Itajaí.

Pelas informações levantadas e sistematizadas em gráficos foi possível compreender o cenário sociocultural e econômico, bem como as necessidades da época, desvelando diversidades, mudanças, curiosidades e interesses, que se revelaram com a evolução da forma de comunicação deste semanário

\section{OS ANÚNCIOS}

A estética a partir do conceito grego Aisthésis, significa percepção, sensação. É uma reflexão filosófica sobre a beleza presente ou não, nas pessoas, objetos e lugares. Assim, é preciso percebê-la e senti-la sendo, portanto um conceito subjetivo. Neste sentido refletimos sobre a forma publicitária utilizada para a divulgação de produtos e serviços na sociedade do período compreendido nessa análise. Para tal, foram analisadas as seguintes informações: localização do anúncio em relação à ocupação das páginas podendo estar no início, meio e fim; tamanho (pequeno, médio e grande); caractere de fonte escrita: língua alemã gótica ou língua alemã latina separadamente; mescla das duas: gótica e latina; e também mescla da língua portuguesa e/ou língua alemã gótica e latina, logomarca (presença de imagens), segmento (especificidade da natureza do anúncio), borda e etnia do anunciante.

Os anúncios tendem a iniciar na mesma página da previsão do tempo (Wetterbericht), denotando grande importância para os leitores em relação à página, haja vista sua provável dependência das condições climáticas para êxito no plantio e produções agrícolas em geral, atividade imprescindível na colônia. Supõe-se ainda que o clima e o solo eram praticamente desconhecidos para grande parte dos imigrantes, que vinham a explorar não somente as terras introduzindo técnicas agrícolas, mas também dependiam das informações para manter as lavouras e as culturas de subsistência.

\subsection{LOCALIZAÇÃO DOS ANÚNCIOS}

Neste item foi analisado dentre as páginas pertencentes aos classificados, qual a posição em média era a mais procurada para inserir os anúncios. Mais da metade dos anúncios estão localizados no meio do jornal e seguem distribuídos de forma praticamente igualitária em relação à posição de início e fim do jornal. 
Assim, percebemos também que os maiores anúncios também ocorrem com maior incidência no meio da publicação, levando-nos a acreditar que estão distribuídos de forma intencional diante da publicação de maior interesse dos leitores.

Nota-se, contudo, que a capa do jornal introduz os assuntos, mas é no decorrer das notícias que o público apresenta maior envolvimento e, portanto, apresenta o maior número de anunciantes com posições de destaque.

\section{LOCALIZAÇÄO NA PÁGINA}

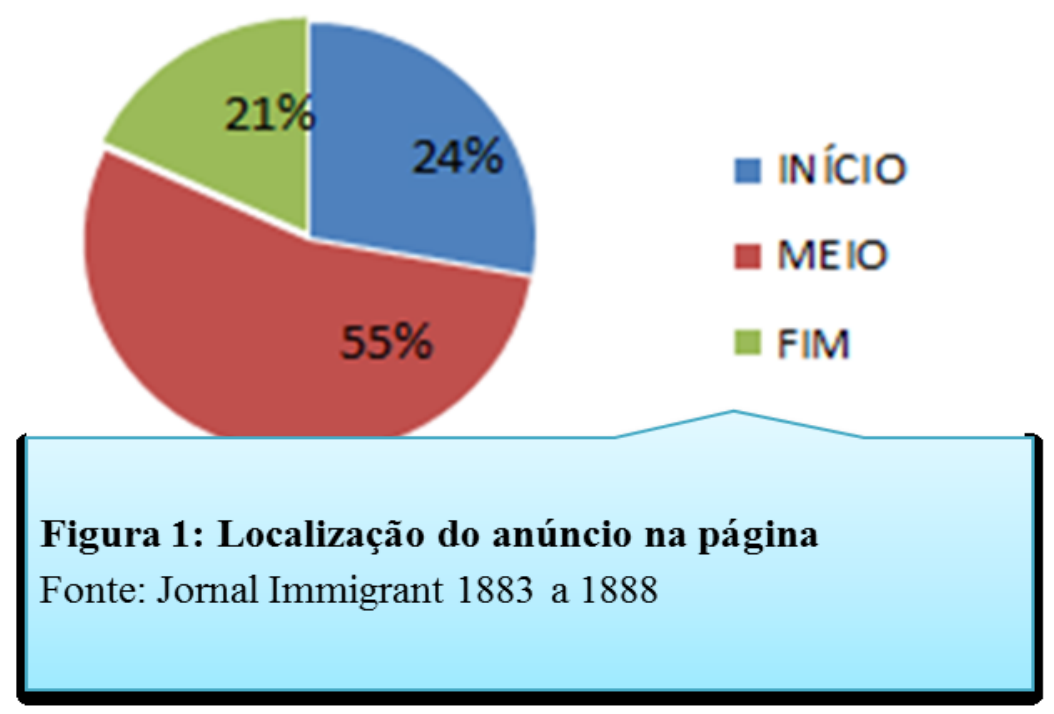

\subsection{TAMANHO DO ANÚNCIO}

Os tamanhos dos anúncios foram divididos e classificados segundo o comparativo de média em três tamanhos padrões: pequeno, médio e grande. Para estabelecer este padrão foram definidas as seguintes nomenclaturas: pequenos ( $2 \mathrm{~cm}$ de altura), medianos (aproximadamente 4 $\mathrm{cm}$ de altura) e grandes anúncios (maiores de $4 \mathrm{~cm}$, geralmente $8 \mathrm{~cm}$ ou mais). Nota-se também que todos os anúncios possuem $8 \mathrm{~cm}$ de largura, que é o tamanho da coluna. Observa-se a importância do anunciante e do anúncio pelo tamanho em que o mesmo encontra-se publicado. Os anúncios menores em sua maioria anunciavam venda de materiais de construção, avisos, venda de produtos agrícolas (tabaco) e editais. Os de tamanho médio por sua vez, tratavam de anúncios de profissionais da saúde, remédios (dentistas, antídoto contra picada de cobra), comunicados de ofertas, prestação de contas de empresas e transporte fluvial. Já os anúncios maiores eram destinados à divulgação dos clubes de caça e tiro, serviços consulares, serviços de impressão gráfica, alguns comunicados da igreja luterana e compra e venda de terrenos e 
propriedades. Aqui se pode inferir também que havia ainda pouco comércio na colônia e os anúncios eram menores e mais baratos, já os anúncios maiores, privilegiavam o negócio imobiliário, o estímulo a participação social com os clubes de caça e tiro e a igreja, elemento característico da imigração alemã, além dos serviços consulares, já que muitos precisavam regularizar sua situação no Brasil.

\section{TAMANHO DO ANÚNCIO}

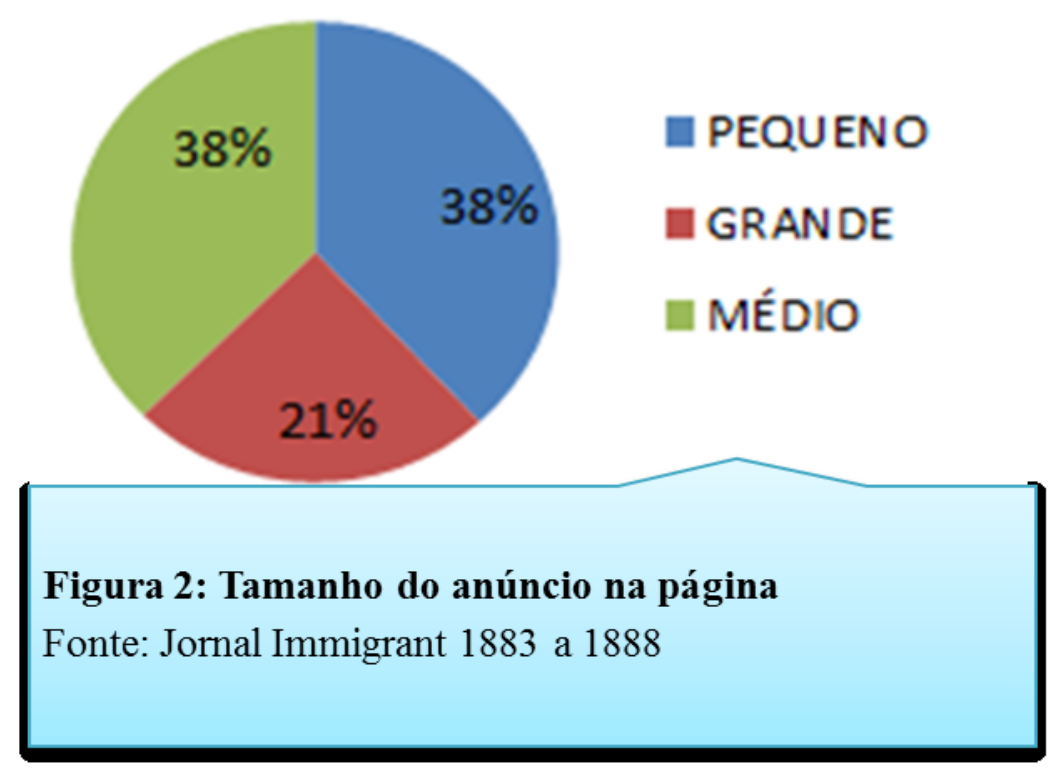

\subsection{LÍNGUA ESCRITA}

Em relação ao uso da escrita, mais da metade dos anúncios foram publicados em língua alemã gótica, seguida pelo uso associado da língua alemã gótica e latina, isto é, muitos anúncios apresentavam uma fusão da escrita gótica alemã com a escrita latina alemã, dessa forma, foi comum encontrar títulos em letras góticas e o corpo de texto em letras latinas em um mesmo anúncio, possivelmente para facilitar a leitura ou mesmo a impressão.

Já a língua portuguesa aparecia de forma bilíngue, principalmente nos anúncios que tratavam de assuntos consulares relacionados com cidadania e naturalização de estrangeiros, assim como os serviços cartoriais, como por exemplo, a emissão de documentos e confecção de escrituras, ou seja, os anúncios publicados em língua portuguesa apareciam acompanhados quase sempre de um "anúncio-tradução", provavelmente para facilitar o entendimento aos imigrantes que ainda não dominavam completamente o idioma nacional. Este fato demonstra que a língua alemã era a língua veicular e da imprensa. Mas a língua portuguesa era a língua administrativa, 
ou seja, todos os trâmites legais eram publicados em português com somente uma tradução em alemão. Observa-se também que os serviços de cartório e consulares eram ofertados por lusobrasileiros, fato que justifica a publicação desses anúncios em português.

\section{LÍNGUA ESCRITA}

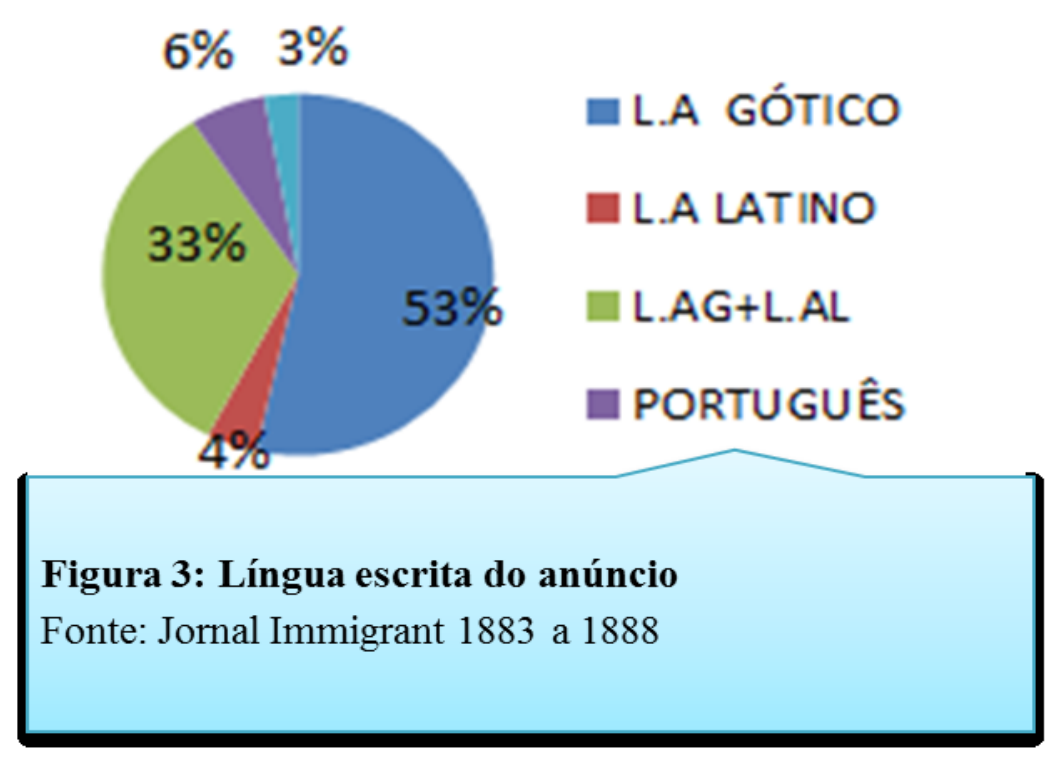

\subsection{SEGMENTO DE PERTENCIMENTO DOS ANÚNCIOS E ETNIA DOS ANUNCIANTES}

Mais da metade das publicações referem-se a prestação de serviços e praticamente todos os anunciantes possuem etnia alemã, não sendo possível afirmar com certeza o sexo do anunciante, pois grande parte deles se apresenta apenas com a abreviação do primeiro nome e o sobrenome dos anunciantes não deixou dúvidas sobre sua procedência e descendência.

Encontrou-se, durante a análise, somente um anunciante sabidamente do sexo feminino, citada como Frau Krämer. No entanto, acredita-se que boa parte dos anunciantes do jornal Immigrant, pertencia ao sexo masculino, pois no referido período, as mulheres não participavam de atividades comerciais. Restringiam-se aos cuidados da casa e das crianças, nas atividades ligadas à agricultura e na produção de mercadorias em geral.

À título de curiosidade, observou-se a venda de antídoto contra picada de cobra (1883) devido provavelmente à grande incidência de cobras, já que a agricultura era a atividade econômica mais predominante na colônia e os imigrantes desbravavam a mata virgem para prover o modo de sobrevivência, quer seja com plantações ou com o próprio assentamento das colônias. 
As publicações de anúncios por luso-brasileiros somam apenas 6\% do total e em sua maioria ofereciam serviços de registro relacionados a processos de naturalização dos imigrantes e serviços de despachante e cartoriais. Reiterando, que tais anúncios se apresentavam muitas vezes duplicados, uma vez em língua alemã e outra em língua portuguesa.

Os serviços ofertados por teuto-brasileiros nos anúncios analisados, eram bem variados, contemplavam serviços de ferreiro, carpinteiro, metalúrgica, hospedagem, pintura, produção de máquinas até atendimento odontológico, e eram oferecidos por colonos dentro da própria colônia. Tais serviços de caráter tão diversificado, faz pensar, que os colonos possivelmente, já traziam consigo algum tipo de conhecimento ou qualificação profissional nas áreas industrial, mecânica e da saúde.

TIPOLOGIA DO ANÚNCIO

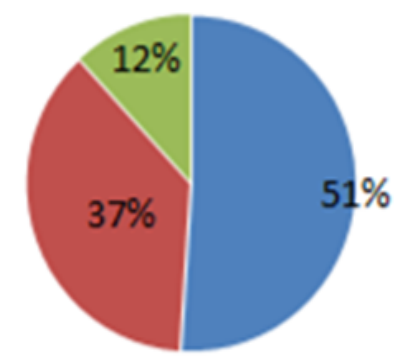

Figura 4: Tipologia do anúncio na página

Fonte: Jornal Immigrant 1883 a 1888

IOUTROS

\section{ETNIA DO ANUNCIANTE}

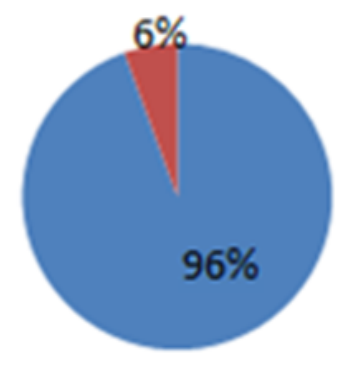

a ALEMÃ

BRASILEIRA

Figura 5: Etnia dos anunciantes

Fonte: Jornal Immigrant 1883 a 1888

\subsection{BORDA E LOGOMARCA DOS ANÚNCIOS}

De acordo com os dados analisados, podemos observar a quase inexistência de recursos sofisticados de publicidade como a utilização de logomarcas e o uso de bordas, provavelmente pelos poucos recursos gráficos disponíveis na época em relação à tecnologia empregada ou mesmo pela ausência de concorrência prevalecendo assim, a forma mais simples de divulgação.

Porém, com o decorrer dos anos, pode-se perceber a maior incidência de recursos tipográficos para chamada de atenção do leitor, como marcas impressas ou letras e iniciais grifadas em negrito. Provavelmente, pelo surgimento de concorrência diante da oferta de produtos e /ou serviços. 
A partir de 1887 pode-se verificar o uso de algum referencial de local como "próximo a", "ao lado de" ou o próprio nome da cidade, indicando um possível crescimento econômico e populacional. Destaca-se o uso de pequenas imagens a partir de 1886 em alguns poucos anúncios, como por exemplo, a imagem de um barco no anúncio de transporte fluvial, denotando um perfil publicitário que remete a realidade atual de leituras imagéticas.
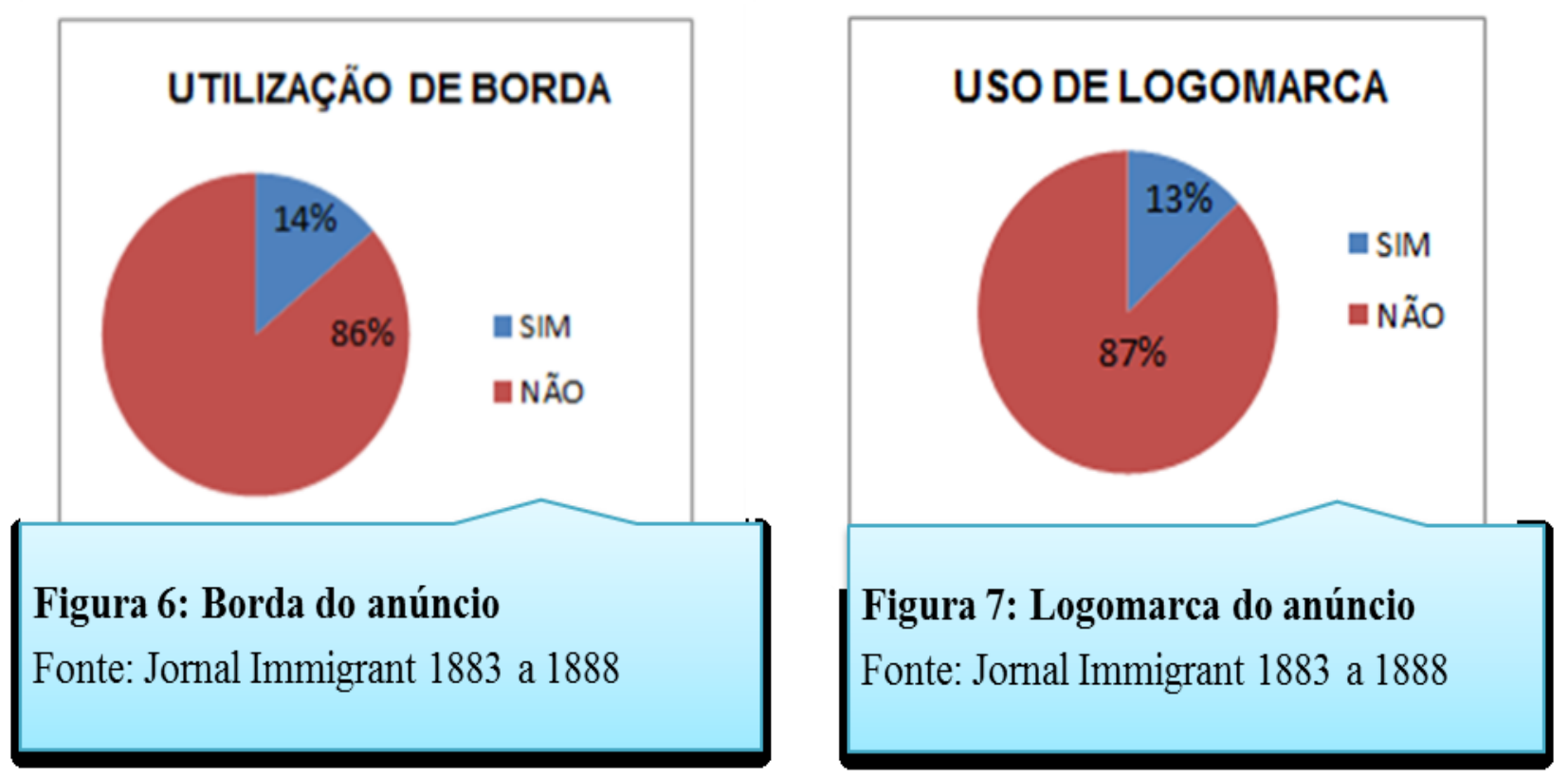

\subsection{FUNÇÃO SOCIAL DOS ANUNCIANTES}

A concepção de função social parte do pressuposto de que o homem deve empregar esforços, no sentido de dar sua contribuição ao bem estar da coletividade em detrimento dos interesses unicamente individuais. Sendo assim, esta concepção visa dar ênfase à importância da consciência de cada indivíduo enquanto ator no cenário da vida em sociedade.

A leitura e a compreensão em termos gerais destes anúncios nos permite inferir elementos que constituem a função social dos anunciantes e leitores, ou seja, quais eram as demandas vigentes na época para o comercio, indústria e setor de serviços. Assim, temos que, os anunciantes, em sua grande maioria, eram imigrantes e teuto-brasileiros, que almejavam vender produtos produzidos por eles próprios, como a manteiga, tijolos, tabaco, óleos, madeira, cimento, produtos agrícolas, etc. A grande incidência de anúncios vendendo materiais de construção (madeira, aço, cimento, tijolos), nos remete a ideia de que a colônia estava em constante expansão. 
A ocorrência de clubes de caça e tiro era perceptível através dos anúncios de prestação de contas, avisos e convites publicados no jornal. Os clubes e associações configuravam o lazer dos imigrantes e teuto-brasileiros, que aparecia como prioridade depois da escola e da Igreja (FIORI; RAMBO, 2003), sendo estes, fortes mantenedores da língua e das tradições trazidas pelos colonos de sua terra natal.

Muitos anúncios apresentavam em relação ao seu conteúdo, negociações de terras e propriedades, cuja unidade de medida era chamada de Morgen $(\mathrm{Mg})$. Morgen era uma unidade de medida utilizada para medir áreas de terras de 2500 até $3500 \mathrm{~m}^{2}$, mas que, no entanto, não apresentava um padrão de tamanho, pois o tamanho era convencionado diferentemente em cada localidade. Na maioria das vezes, o Morgen compreendia um quinto até meio hectare.

$\mathrm{Na}$ primeira edição analisada, a venda de matéria-prima como aço está evidente nos anúncios. Logo, acredita-se que os ferreiros compravam-no para confecção de ferramentas e máquinas agrícolas para uso na colônia, possibilitando o crescimento da indústria local, cujo reflexo ocasionou provavelmente uma expansão econômica da região.

Alguns nomes se repetem em anúncios e edições/anos diferentes, em todas as amostras analisadas, remetendo assim à figura e ao perfil de investidores como Gustav Salinger (compra de dividendos da Cia Marítima de Navegações), Eugen Currlin e Victor Gaertner.

Como principais produtos podemos destacar a venda de propriedades e de terrenos em Morgens, a venda de máquinas e equipamentos industriais seguidas pela venda de produtos para consumo próprio como verduras, legumes, farinhas, cafés, tabaco, querosene, óleo de rícino, sabão, entre outros, bem como a venda de livros, revistas e jornais.

Como principais serviços podem ser destacados os serviços de hospedagem em pensões e hotéis, os serviços de transporte fluvial, tanto para cargas como para pessoas, oferta de serviços consulares e cartoriais para registro e regularização de imigrantes e transações imobiliárias.

Além disso, vale ressaltar os diversos avisos da Igreja, cujos horários, programações e prestações de contas eram divulgados ao público imigrante alemão. E ainda, editais com chamadas públicas, notificações de festas e eventos sociais, comemorações de bodas, entre outros, apresentam-se de forma assídua nas edições analisadas.

Convém ressaltar que os anúncios de produtos e serviços compilados foram traduzidos individualmente e assim, reunidos, agrupados e transpostos em tabela para que o conteúdo real não fosse perdido e servissem de base para as análises.

Através da tabela do anexo A é possível verificar de forma mais minuciosa dos bens de consumo, serviços e comunicados encontrados em todas as amostras analisadas bem como a respectiva quantidade de reincidência por ano de publicação. 


\subsection{ANÁLISE LINGUÍSTICA}

A prática da análise linguística constitui-se em um instrumental capaz de refletir a organização do texto escrito. Desta forma, a importância da língua falada e escrita revela-se diante da cultura de um povo e de todo referencial de identidade nela contido e pode ser analisado diante dos registros linguísticos encontrados na época.

Assim, convém ressaltar que dos 144 espaços publicitários analisados, 53\% encontramse escritos em Língua Alemã Gótica, um alfabeto que entrou em declínio na Primeira Guerra Mundial (1914-1918) e foi praticamente extinto ao fim da Segunda Guerra Mundial (19391945).

Desta forma, o uso corrente desse alfabeto implica na reflexão de que a leitura e a escrita em gótico identificam provavelmente pessoas alfabetizadas, ainda que em períodos entre guerras. Em termos gerais, o gótico alemão adentra uma complexa rede de símbolos religiosos e a construção de imagens que expressavam a devoção ao poder monárquico e podem ser retratados de forma gráfica, no campo da literatura.

Destes anúncios, 33\% apresentam a língua alemã gótica associada à escrita da língua alemã latina. $6 \%$ dos anúncios estão escritos em língua portuguesa, 4\% em língua alemã latina e $3 \%$, em língua portuguesa associada ao uso da língua alemã, principalmente utilizada como tradução do texto publicado.

Anúncios bilíngues, ou seja, que aparecem tanto em língua alemã, como em língua portuguesa, ocorreram principalmente em cartas de naturalização para os teuto-brasileiros e podem ser observados no primeiro ano deste jornal (1883).

Após este período, percebe-se o interesse que os anunciantes mantêm em ampliar o alcance dos anúncios, atingindo também uma população que tem a língua portuguesa como língua oficial e ou sofrendo forte pressão do governo em relação ao uso da língua portuguesa como forma de comunicação que deveria ser adotada na prática.

Infere-se, portanto, que a língua alemã está diretamente associada à questão da identidade dos imigrantes e evidenciada através de suas relações de consumo, cuja importância revela-se percentualmente através de $91 \%$ dos anúncios publicados entre o período de 1883 a 1888.

\section{CONSIDERAÇÕES FINAIS}

Este trabalho demonstra a importância das relações comerciais que implica no entendimento de toda uma nova sociedade que surgia em solo brasileiro na Região do Vale do 
Itajaí no período de colonização alemã. Através dos anúncios foi possível entender um pouco mais sobre as perspectivas e modo de vida dos imigrantes.

Nesta mesma época, publica-se um anúncio de venda de uma cervejaria completa, ou seja, os teuto-brasileiros trouxeram as técnicas e processos de fabricação da cerveja que naquela época já era uma bebida bastante popular na Alemanha.

Pelos anúncios, percebe-se também, que o transporte mais utilizado era o fluvial, tanto para o transporte de passageiros, como no transporte de mercadorias. As viagens de barco estavam previstas para uma ocorrência a cada cinco dias, conforme horários descritos no anúncio.

A igreja luterana ocupa lugar de destaque no jornal, nas páginas de anúncios se percebe uma série de avisos e também a publicação da programação e horários de cultos, prestação de contas e demais comemorações, o que demonstra o papel significativo da igreja luterana na comunidade de imigrantes.

Além dos avisos paroquiais e dos editais, surgem outras publicações como a retirada de circulação de uma série de notas de dinheiro, provavelmente início de uma reforma monetária.

Em 1887 a 1888 começam a surgir anúncios com produtos muito sofísticados como caviar, vinhos e chocolates finos, o que traz a ideia da presença de uma possível elite, potencialmente composta por investidores e empresários locais.

Acredita-se que o público, ao qual o jornal se destinou seja composto por leitores de livros, revistas e jornais tanto publicados aqui quanto trazidos da Alemanha.

Numa edição de 1884 há um anúncio recrutando com urgência um professor para uma escola alemã. Cabe ressaltar que as escolas alemãs eram instituições privadas muito valorizadas e priorizadas pelas colônias. A partir disso, nota-se uma provável competência linguística por parte dos imigrantes e teuto-brasileiros, tanto na oralidade como na escrita da norma padrão, e tal percepção pode ser atribuída à priorização da implantação de escolas, que eles mesmos idealizaram, chamadas de Escolas Comunitárias ou Escolas Alemãs. As escolas teuto-brasileiras foram fundadas por associações ou sociedades (Schulverein ou Schulgemeinde), formadas por famílias locais, e algumas escolas estavam também, vinculadas à igreja evangélica, principalmente à luterana e eram subsidiadas pelas próprias famílias teuto-brasileiras (SANTOS, 2014).

Há presença de anúncios sobre uma revista sediada em Berlim que oferece informações sobre como fazer importação e exportação de produtos produzidos na colônia.

Um anúncio bastante peculiar chama a atenção pelo interesse de um determinado anunciante que deseja questionar o destino correto do lixo na cidade de Blumenau. 
Publicam-se alguns anúncios com oferta de serviços bastante especializados como, por exemplo, o de odontologia. A presença de anunciantes oferecendo óleo de rícino também é interessante ser destacada, tendo em vista o seu uso para a cura de diversos males, como problemas gastrointestinais, distúrbios menstruais, infecções, etc.

Dessa forma, foi possível, por meio da análise dos anúncios do jornal Immigrant, visualizar o contexto econômico cultural da colônia com suas atividades comerciais, de serviços, de lazer e até mesmo o início da industrialização no Vale do Itajaí. Percebe-se que a língua alemã foi o idioma no qual o município se constituiu como tal e foi um dos elementos de identidade da comunidade teuto-brasileira. Pela grande quantidade de material impresso na época constata-se que a população da região estava inserida em práticas de letramento e se utilizava da leitura e da escrita no cotidiano. A atuante imprensa alemã, além de revelar a vida, conflitos, anseios, sonhos e esperanças dos imigrantes, contribuiu consideravelmente não só para a manutenção da língua alemã padrão, como também constituiu-se em ferramenta de estímulo e construção de conhecimento dos imigrantes e seus descendentes.

\section{REFERÊNCIAS}

FIORI, Neide A.; RAMBO, Arthur B. Etnia e educação: a escola "alemã" do Brasil e estudos congêneres. Florianópolis : Ed. UFSC; Tubarão : Ed. UNISUL, 2003. 258 p.

IMMIGRANT. Blumenau. [jornal] 1883 - 1888.

MAILER, Valéria C. O. O Alemão em Blumenau: uma questão de identidade e cidadania. 2003. Dissertação de mestrado. UFSC. Florianópolis, 2003.

O NASCIMENTO da imprensa em Blumenau. Disponível em $<$ https://furbjornalismo.wordpress.com/jornais-pioneiros/>. Acesso em: 08 out 2016.

SANTOS, Ademir V. As escolas alemãs em Santa Catarina e sua transformação para teutobrasileiras: uma análise histórica. Acta Scientiarum. Education Maringá, v. 36, n. 2, p. 233-242, Jul. - Dez. 2014.

SEYFERTH, Giralda. A dimensão cultural da imigração. Rev. bras. Ci. Soc. [online]. 2011, vol.26, n.77, pp.47-62. ISSN 1806-9053. http://dx.doi.org/10.1590/S010269092011000300007.

SILVA, J. Ferreira. A imprensa em Blumenau. Florianópolis: Secretaria da Educação e Cultura. 1977. 


\section{ANEXO A - TABELA DE CLASSIFICAÇÃO DOS ANÚNCIOS}

\begin{tabular}{|c|c|}
\hline ESPECIFICAÇÃO DOS ASSUNTOS TRATADOS - ANÚNCIOS -1883 & $\begin{array}{l}\text { REINCIDÊNCI } \\
\text { AS }\end{array}$ \\
\hline Venda de produtos variados & 2 \\
\hline Venda de madeira & 2 \\
\hline Venda de Tabaco & 1 \\
\hline Hotel (Blumenau) & 1 \\
\hline Despachante & 2 \\
\hline Clube caça e tiro & 1 \\
\hline Cervejaria & 1 \\
\hline Venda de produtos de limpeza e roupas & 1 \\
\hline Reunião associação agrícola & 1 \\
\hline Avisos & 4 \\
\hline Venda de cimento & 2 \\
\hline Serviço de fotografia & 1 \\
\hline Serviço de correspondência & 1 \\
\hline Venda de aço & 2 \\
\hline Venda de terras/ propriedades & 3 \\
\hline Venda de tijolos & 1 \\
\hline Venda de carrinho de mão & 1 \\
\hline Oferta de emprego & 1 \\
\hline Transporte Fluvial & 2 \\
\hline Venda de Manteiga & 1 \\
\hline Antídoto contra picada de cobra & 1 \\
\hline Dentista & 1 \\
\hline Compra de peles de aves & 1 \\
\hline Convocação dos acionistas do jornal & 1 \\
\hline Venda de máquinas agrícolas (trituradoras) & 1 \\
\hline Comunicado de ofertas & 1 \\
\hline Venda de couro & 1 \\
\hline ESPECIFICAÇÃO DOS ASSUNTOS TRATADOS - ANÚNCIOS -1884 & $\begin{array}{l}\text { REINCIDÊNCI } \\
\text { AS }\end{array}$ \\
\hline Venda de Serviços - Viagens e transporte marítimo (pessoas e cargas) & 1 \\
\hline Venda de Serviços consulares e de cartório (legalização) & 2 \\
\hline
\end{tabular}




\begin{tabular}{|c|c|}
\hline ESPECIFICAÇÃO DOS ASSUNTOS TRATADOS - ANÚNCIOS -1883 & $\begin{array}{l}\text { REINCIDÊNCI } \\
\text { AS }\end{array}$ \\
\hline Venda de Serviços de Hospedagem (Hotel, Pensão) & 3 \\
\hline Venda de Serviços (Pintura - Malerei) & 1 \\
\hline Venda de Serviços de Consertos/Amolador & 1 \\
\hline Venda de Produtos para a Indústria (Máquinas diversas e Máquina para fabricação de manteiga) & 2 \\
\hline Venda de Produtos para Consumo (Óleo de Rícino) & 2 \\
\hline Venda de Produtos para Consumo (Caviar, vinho, chocolates, outros) & 1 \\
\hline Venda de Produtos para Consumo (Pepinos) & 1 \\
\hline Venda de Produtos para Consumo (Tabacos e Cachimbos) & 1 \\
\hline Venda de Produtos para Consumo (Farinha, querosene e café) & 1 \\
\hline Venda de Produtos para Consumo (Amendoim) & 1 \\
\hline Venda de terreno (em Morgens) & 4 \\
\hline Venda de Serviços (Tabacarias) & 1 \\
\hline Revistas e Jornais & 2 \\
\hline Apresentação e Programação de Coral & 1 \\
\hline Avisos Paroquiais e Prestação de Contas Igreja & 5 \\
\hline Aviso de Notas Fora de Circulação & 1 \\
\hline Anúncio de Festa e comemorações & 2 \\
\hline Aviso de Formalização de Compra de Terrenos & 1 \\
\hline Programação de Associação & 1 \\
\hline Venda de meias e roupas intimas sob encomenda, direto com fabricante. & 1 \\
\hline Venda de frutas e verduras. & 1 \\
\hline Venda de amendoim e nozes. & 1 \\
\hline Venda de serviços com negociações, cartório, anúncios de expedições, patentes etc. & 1 \\
\hline $\begin{array}{l}\text { Oportunidade de trabalho para revender calendários de parede "Immigrant". Para revender teria } \\
20 \% \text { de desconto. }\end{array}$ & 1 \\
\hline Contratação de um professor urgente até $1^{\circ}$ de Maio. & 1 \\
\hline $\begin{array}{l}\text { Convite para festa de comemoração do jubileu de } 25 \text { anos da } \\
\text { empresa. }\end{array}$ & 1 \\
\hline $\begin{array}{l}\text { Prestar contas à sociedade sobre a contabilidade da empresa conforme lei de responsabilidade } \\
\text { fiscal. }\end{array}$ & 1 \\
\hline Aviso de assembleia geral para discutir promessas gerais entre outras. & 1 \\
\hline Contratação imediata de um rapaz de recados. & 1 \\
\hline Procura de uma pessoa jovem para estudar para escritor do jornal & 1 \\
\hline Horários dos cultos. & 2 \\
\hline
\end{tabular}




\begin{tabular}{|c|c|}
\hline ESPECIFICAÇÃO DOS ASSUNTOS TRATADOS - ANÚNCIOS -1883 & $\begin{array}{l}\text { REINCIDÊNCI } \\
\text { AS }\end{array}$ \\
\hline Horários de missa. & 1 \\
\hline Horários de saída da embarcação. & 2 \\
\hline Papelaria venda de livros, contos, cartilhas, papéis de carta e muitos outros. & 1 \\
\hline Revista mensal sediada em Berlin sobre importação e exportação: anúncio de venda. & 1 \\
\hline Compra e venda e troca de moeda e objetos. & 1 \\
\hline Venda de um terreno em Gaspar em condições & 3 \\
\hline $\begin{array}{l}\text { Venda de farinha de trigo em Itajaí em porções de } 10 \text { barricas diversas marcas. } 20 \text { reis a barrica. } \\
\text { Venda só a dinheiro. }\end{array}$ & 1 \\
\hline $\begin{array}{l}\text { Questionando ou oferecendo trabalho para dar fim correto ao destino do lixo na cidade de } \\
\text { Blumenau. }\end{array}$ & 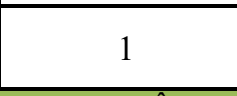 \\
\hline ESPECIFICAÇÃO DOS ASSUNTOS TRATADOS - ANÚNCIOS -1887 E 1888 & $\begin{array}{l}\text { REINCIDÊNCI } \\
\text { AS }\end{array}$ \\
\hline Venda de Serviços - Viagens e transporte marítimo (pessoas e cargas). & 1 \\
\hline Venda de Serviços consulares e de cartório (legalização). & 2 \\
\hline Venda de Serviços de Hospedagem (Hotel, Pensão). & 3 \\
\hline Venda de Serviços (Pintura - Malerei). & 1 \\
\hline Venda de Serviços de Consertos/Amolador. & 1 \\
\hline Venda de Produtos para a Indústria (Máquinas diversas e Máquina para fabricação de manteiga). & 2 \\
\hline Venda de Produtos para Consumo (Óleo de Rícino). & 2 \\
\hline Venda de Produtos para Consumo (Caviar, vinho, chocolates). & 1 \\
\hline Venda de Produtos para Consumo (Pepinos). & 1 \\
\hline Venda de Produtos para Consumo (Tabacos e Cachimbos). & 1 \\
\hline Venda de Produtos para Consumo (Farinha, querosene e café). & 1 \\
\hline Venda de Produtos para Consumo (Amendoim). & 1 \\
\hline Venda de terreno (em Morgens). & 4 \\
\hline Venda de Serviços (Tabacarias). & 1 \\
\hline Revistas e Jornais. & 2 \\
\hline Apresentação e Programação de Coral. & 1 \\
\hline Avisos Paroquiais e Prestação de Contas Igreja. & 5 \\
\hline Aviso de Notas Fora de Circulação. & 1 \\
\hline Anúncio de Festa e comemorações. & 2 \\
\hline Aviso de Formalização de Compra de Terrenos. & 1 \\
\hline
\end{tabular}

Fonte: Jornal Immigrant 1883 a 1888 


\section{ANEXO B - Imagem da capa do Jornal Immigrant}

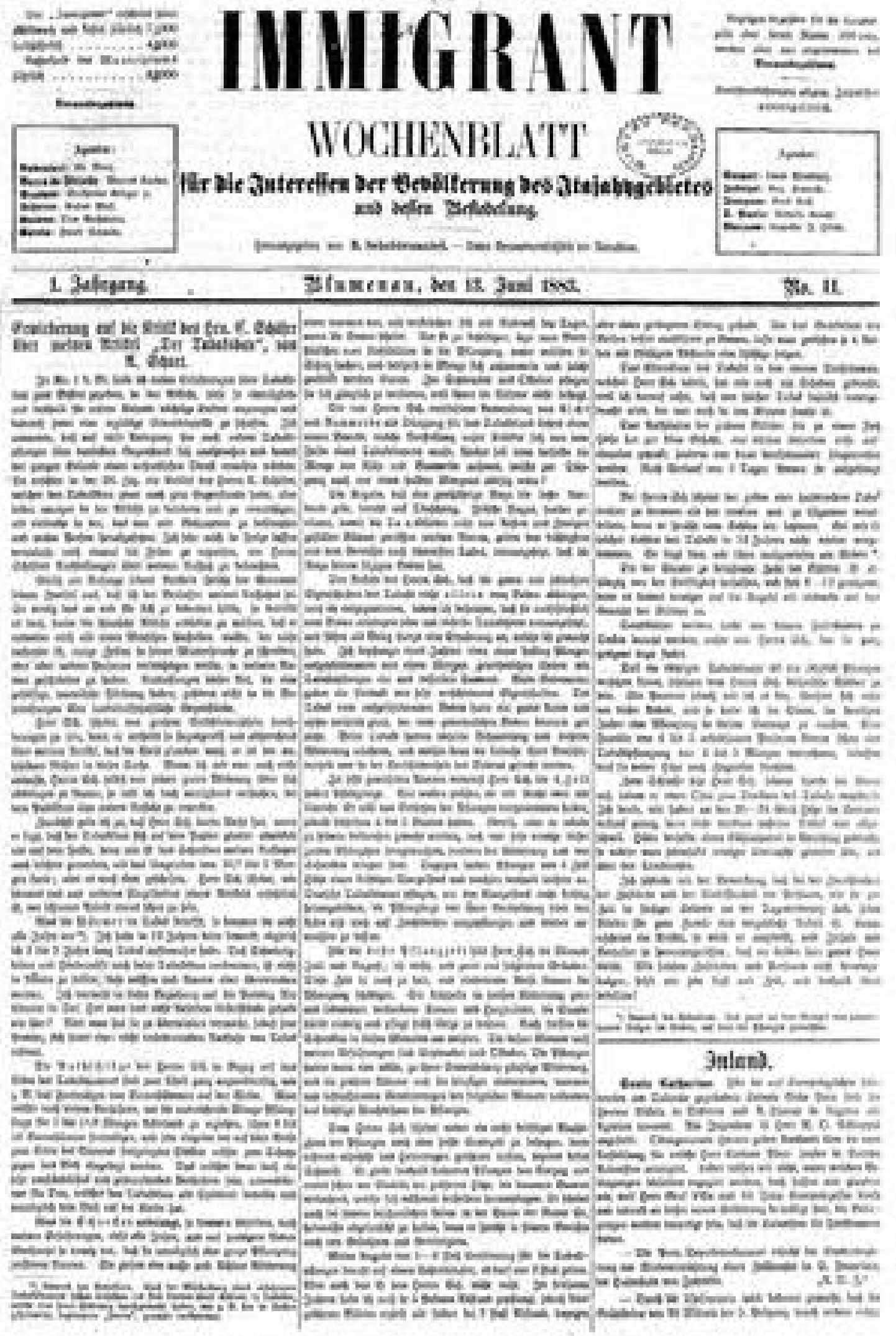




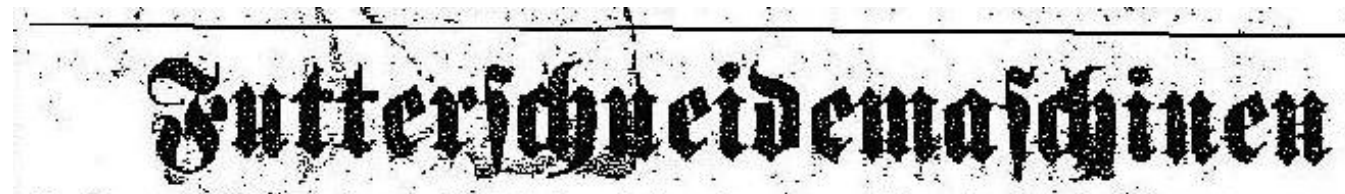

bejontors praftiju für ben Solonitten, ba man 3utecrohr, Slipin=stetgd, grinten pais etc. Darall fductoelt fnitt.

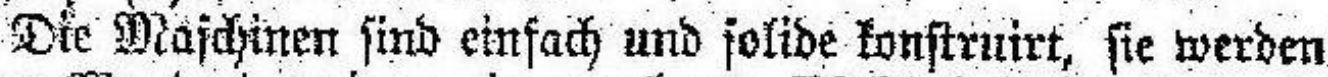

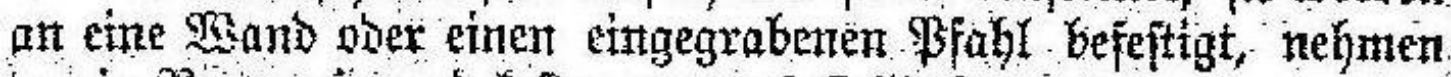
tonig Ratm etit mo fofter rut 10 \$OOO.

Setuflehfyubr wollen fid wenten ant

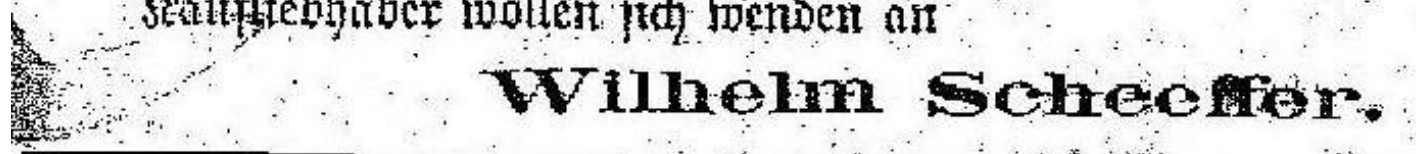

Fonte: Jornal Der Immigrant 1883.

TRADUÇÃO:
MÁQUINA DE CORTAR TRATO
MUITO PRÁTICA PARA OS COLONOS, CORTA
CANA-DE-AÇUCAR, RAMOS DE MANDIOCA, MILHO
VERDE, ETC.
As máquinas são simples e solidamente
construídas, elas podem ser fixadas na parede ou sobre um poste, ocupam pouco espaço e custam apenas $40 \$ 000$.

Interessados entrar em contato com

Wilhelm Scheeffer 